\title{
DAMPAK DIGITALISASI TERHADAP PERAN FRONT OFFICE DALAM BISNIS PERBANKAN
}

\author{
Salmah ${ }^{1}$, Andreas Murti ${ }^{2}$ \\ 1,2Universitas Pakuan, Bogor, Indonesia \\ Email: salmah@unpak.ac.id
}

\begin{abstract}
This study aims to review and analyze the impact of banking digitalization to front office functions in the banking business in the city of Bogor. Data collection was carried out by gathering information from stakeholders and branch managers of the two state-owned banks in Bogor City through questionnaires and interviews with informants. The data processed in a descriptive statistics methods. The results of data collection from 2016-2018 at ABC Bank showed fairly consistent growth for transactions with m-banking and internet banking. While for XYZ Bank, transaction with m-banking increased significantly, while transactions through internet banking declined slightly, but in total both transactions increase significantly. This shows the preferences of XYZ bank customers who tend to use smartphones in banking transactions. The majority of respondents agreed that $m$-banking and internet banking with all the conveniences and features that are constantly being updated will be able to take over the role and duties of the front office in the future. Teller and customer service must adapt with technology and continue to develop their skill so they can compete and keep contributing in banking business.
\end{abstract}

Keywords: banking, digitalization, front office, internet banking, mobile banking.

\section{ABSTRAK}

Penelitian ini bertujuan untuk mengetahui dan menganalisis dampak digitalisasi perbankan terhadap peran front office yaitu Teller dan Customer Service dalam bisnis perbankan di kota Bogor. Pengumpulan data dilakukan dengan mengumpulkan informasi dari stakeholder dan pimpinan cabang dua bank BUMN di Kota Bogor melalui penyebaran kuesioner dan wawancara kepada para narasumber. Data yang diolah menggunakan metode statistik deskriptif. Hasil pengumpulan data dari tahun 2016-2018 pada Bank ABC menunjukan pertumbuhan yang cukup konsisten untuk transaksi perbankan melalui mobile banking dan internet banking. Sementara untuk Bank XYZ pertumbuhan transaksi melalui mobile banking meningkat secara signifikan, sementara transaksi melalui internet banking sedikit mengalami penurunan, namun secara total transaksi melalui mobile banking dan internet banking mengalami peningkatan yang cukup besar. Hal ini menunjukan preferensi nasabah bank XYZ yang cenderung menggunakan smartphone dalam melakukan transaksi perbankannya. Mayoritas responden setuju bahwa mobile banking dan internet banking dengan segala kemudahan dan fitur yang terus diperbaharui akan dapat mengambil alih peran dan tugas front office kedepannya. Teller dan customer service harus beradaptasi dengan teknologi dan terus mengembangkan skill sehingga dapat bersaing dan tetap berkontribusi dalam bisnis perbankan berdampingan dengan digitalisasi yang terus berkembang dalam dunia perbankan saat ini.

Kata kunci: digitalisasi, perbankan, front office, internet banking, mobile banking

KETERANGAN ARTIKEL

Riwayat Artikel: diterima: 30 Mei 2020; direvisi: 11 November 2020 ; disetujui: 28 November 2020

Klasifikasi JEL: G30, 016

Cara Mensitasi: Salmah dan Murti, A. (2020). Dampak Digitalisasi terhadap Peran Front Office dalam Bisnis

Perbankan. JIMFE (Jurnal IImiah Manajemen Fakultas Ekonomi), 6(2), 145-156.

https://doi.org/10.34203/jimfe.v6i2.2055

Copyright@2020. JIMFE (Jurnal IImiah Manajemen Fakultas Ekonomi) Universitas Pakuan 
Salmah: Dampak Digitalisasi terhadap ...

\section{PENDAHULUAN}

Industri perbankan merupakan salah satu industri yang memiliki peranan penting dalam menggerakkan perekonomian suatu negara. Hal ini karena aktifitas utama perbankan adalah menghimpun dana dari masyarakat (funding) dan menyalurkan dana kepada masyarakat (lending). Namun, sejalan dengan perkembangan bisnis, perbankan tidak hanya memberikan jasa dalam penghimpunan dan penyaluran dana, tetapi berkembang luas pada layanan jasa keuangan lainnya, seperti jasa pemindahan uang (transfer), jasa penagihan (inkaso), jasa kliring (clearing), jasa penjualan mata uang asing (valas), jasa safe deposit box, travellers cheque, bank card, bank draft, L/C, bank garansi, dan lainnya.

Banyaknya jasa yang ditawarkan oleh perbankan dan munculnya perusahaan-perusahaan rintisan (startup) finansial yang dikenal dengan istilah Fintech, menuntut perbankan untuk terus melakukan development dan improvement terhadap produk-produk dan layanan yang ditawarkan kepada customer. Salah satu bentuk pengembangan yang dilakukan oleh perbankan adalah menerapkan dan memanfaatkan teknologi digital dalam proses bisnisnya dan juga dalam pembuatan produk-produk perbankan dan layanan yang ditawarkan kepada customer.

Teknologi digital merupakan peralihan dari operasional yang tidak lagi banyak menggunakan tenaga manusia, tetapi lebih cenderung pada sistem pengoperasian yang serba otomatis dan canggih dengan komputer. Pesatnya perkembangan teknologi digital yang ditandai dengan kehadiran berbagai alat komunikasi mutakhir, di mana setiap orang dapat mengolah, memproduksi, serta mengirimkan maupun menerima segala bentuk pesan komunikasi di mana saja dan kapan saja tanpa batasan ruang dan waktu (Wike dan Fika, 2018).

Perkembangan

telekomunikasi dan informasi memberi dampak terhadap perubahan perilaku masyarakat termasuk perilaku masyarakat Indonesia. Perubahan perilaku masyarakat yang saat ini sangat tergantung pada internet melalui komputer dan smartphone menyebabkan terjadinya perubahan terhadap perilaku konsumen termasuk konsumen bank. Sebagai contoh, nasabah perbankan yang dahulu harus datang ke kantor/cabang bank untuk melakukan transaksi layanan keuangan, dengan adanya teknologi dalam bentuk jaringan internet nasabah sudah dapat menikmati layanan keuangan di mana saja dan kapan saja.

Perubahan perilaku konsumen yang mengarah kepada teknologi mendorong industri perbankan untuk terus meningkatkan mutu dan pelayanannya. Saat ini dunia perbankan berlomba-lomba mengembangkan produk dan layanan berbasis teknologi digital. Layanan perbankan dengan sentuhan digitalisasi yang dapat dinikmati oleh nasabah saat ini, yaitu ATM, SMS Banking, Internet Banking, dan M-Banking. Transaksi melalui e-banking tumbuh cukup signifikan. Berdasarkan data 13 bank besar di Indonesia, frekuensi transaksi melalui e-banking pada 2012 tercatat 3,79 miliar transaksi dengan nominal Rp4,441 triliun, kemudian meningkat menjadi 4,73 miliar transaksi dengan nominal Rp5,495 Triliun pada 2013 dan menjadi 5,69 miliar transaksi dengan nominal Rp6,447 triliun pada tahun 2014. Pertumbuhan tersebut berpotensi terus meningkat setiap tahunnya. Hal ini memacu bank-bank di Indonesia fokus dalam menggarap digital banking. Salah satunya adalah PT Bank Rakyat Indonesia yang melakukan ekspansi dalam pengembangan layanan maupun infrastruktur melalui peluncuran satelit BRI atau BRI Sat yang diluncurkan pada tahun 2015. Hal ini juga diikuti oleh beberapa bank yang fokus terhadap digital banking seperti MNC Bank yang pada tahun 2016 meluncurkan aplikasi M-Banking (ProBank, 2016).

Keseriusan perbankan dalam menggarap digital banking untuk meningkatkan layanan dan mutunya agar 
tetap dapat bersaing dalam lingkungan bisnis yang kompetitif, memunculkan isu atau kekhawatiran baru dari sisi Sumber Daya Manusia (SDM). Penggunaan teknologi pada beberapa layanan perbankan mengakibatkan berkurangnya pekerjaan yang dilakukan manusia. Penerapan digitalisasi banking memangkas proses administrasi bank yang berbelit dan memakan banyak waktu sekaligus juga memangkas atau menghilangkan sejumlah pekerjaan yang biasanya dikerjakan oleh manusia terutama pekerjaan front office.

Pusat informasi, Data dan Komunikasi Atlantika Institut Nusantara menyimpulkan bahwa profesi karyawan bank yang tengah terancam oleh kehadiran teknologi digital mulai sekarang di antaranya adalah pekerjaan di bagian teller dan customer service. Hal ini disebabkan oleh beragam produk digital banking yang memungkinkan nasabah untuk melakukan transaksi di mana saja dan kapan saja sehingga transaksi yang tadinya membutuhkan tatap muka dengan teller dan customer service dapat digantikan dengan mesin, ditambah lagi dengan wacana Branchless Banking yang menghadirkan bank tanpa kantor dan nasabah hanya akan dilayani oleh layar monitor saja akan mengakibatkan berkurangnya kebutuhan bank terhadap karyawan front office yang sebelumnya dibutuhkan untuk bertatap muka dengan nasabah (Ereste dan Ratuate, 2018).

Dengan kondisi di atas diperlukan suatu kajian untuk mengetahui dampak nyata dari digitalisasi banking terhadap peran teller dan customer service dalam kegiatan bisnis perbankan sebagai garda terdepan dalam pemberian layanan kepada nasabah. Kajian akan dilakukan pada peran teller dan customer service pada dua bank BUMN yang berada di Kota Bogor sehingga dapat menunjukkan dampak signifikan dari penggunaan digitalisasi banking pada posisi teller dan customer service dalam kegiatan bisnis bank.

Adapun tujuan dari penelitian ini adalah untuk mengetahui dan menganalisis dampak yang ditimbulkan dari penerapan digitalisasi banking secara langsung terhadap fungsi dan tugas teller dan customer service pada kegiatan bisnis perbankan pada dua bank BUMN di Kota Bogor, yaitu Bank ABC dan Bank $X Y Z$. Untuk mendapatkan gambaran dampak langsung digitalisasi terhadap fungsi dan tugas front office dalam penelitian ini digunakan data jumlah nasabah yang bertransaksi melalui teller dan customer service selama tiga tahun. Selain itu juga penelitian ini dilengkapi dengan pernyataan dari para pimpinan cabang langsung mengenai dampak digitalisasi yang mereka rasakan pada peran front office di cabangnya masing-masing.

\section{KAJIAN LITERATUR \\ Perbankan}

Menurut Undang-Undang Perbankan No. 7 Tahun 1992 tentang Perbankan yang telah diubah menjadi Undang-Undang No. 10 Tahun 1998, mengartikan bank sebagai perusahaan yang bergerak di bidang jasa dan memiliki kegiatan pokok dengan tiga fungsi pokok, sebagai berikut: menerima penyimpanan dana masyarakat dalam berbagai bentuk, menyalurkan dana tersebut dalam bentuk kredit kepada masyarakat untuk mengembangkan usaha, dan melaksanakan berbagai jasa dalam kegiatan perdagangan dan pembayaran dalam negeri maupun luar negeri serta berbagai jasa lainnya di bidang keuangan (IBI, 2013).

Bank dalam melaksanakan kegiatannya mempunyai kebebasan untuk menentukan produk dan jasanya. Kegiatan menghimpun dana masyarakat dilakukan melalui penjualan produk dana dalam bentuk Giro, Tabungan, Deposito dan Sertifikat Deposito. Kegiatan menyalurkan dana dilakukan melalui penyaluran kredit dalam berbagai bentuk seperti Kredit Investasi, Kredit Modal Kerja, Kredit Konsumtif, Kredit tanpa jaminan, dll. Kegiatan jasa perbankan merupakan kegiatan yang dilakukan perbankan untuk memperlancar terjadinya transaksi perdagangan, memperlancar peredaran uang, dan memberikan jaminan kepada nasabahnya. 
Salmah: Dampak Digitalisasi terhadap ...

Beberapa jasa yang ditawarkan oleh perbankan antara lain transfer, inkaso, kliring, BI-RTGS, bank draft, traveller's cheque, letter of credit, bank garansi, safe deposit box, jual beli valuta asing dan electronic banking.

Elektronic banking adalah salah satu produk jasa perbankan yang saat ini paling diminati oleh masyarakat seiring dengan perkembangan teknologi dan kebutuhan masyarakat yang semakin beragam. Elektronic banking atau dikenal dengan e-banking merupakan sistem yang memungkinkan nasabah bank baik individu ataupun bisnis untuk mengakses rekening, melakukan transaksi bisnis, atau mendapatkan informasi produk dan jasa bank melalui jaringan pribadi atau publik termasuk internet. Penyelenggaraan e-banking merupakan penerapan atau aplikasi teknologi informasi yang terus berkembang dan dimanfaatkan untuk menjawab keinginan nasabah perbankan yang menginginkan servis cepat, aman, nyaman, murah, dan tersedia setiap saat 24 jam/hari dan dapat diakses dari mana saja (Rosa, 2016).

\section{E-Banking}

Bank menyediakan layanan electronic banking atau e-banking untuk memenuhi kebutuhan nasabah akan alternatif media untuk melakukan transaksi perbankan selain yang tersedia di kantor cabang dan Anjungan Tunai Mandiri (ATM). Dengan electronik banking, nasabah tidak perlu lagi membuang waktu antri di kantor-kantor bank atau ATM (Aryani dan Aris, 2015)

E-banking terdiri dari Internet banking dan SMS Banking. Internet banking adalah fasilitas layanan perbankan yang nyaman dan aman diberikan kepada nasabah melalui jaringan Internet, kapan saja, di mana saja, yang mempermudah nasabah untuk transaksi perbankan yang diantara nya yaitu cek saldo, mutasi rekening sampai transfer, pembayaran tagihan dan perencanaan keuangan. SMS Banking merupakan fasilitas layanan perbankan yang diantaranya yaitu memudahkan nasabah untuk melakukan isi ulang pulsa, transfer (Rinda dan Elsy, 2017).

\section{Front Office}

Petugas front office pada sebuah bank adalah karyawan yang ditugaskan pada garda terdepan untuk melayani kebutuhan perbankan nasabah baik dengan tatap muka ataupun melalui alat komunikasi lainnya seperti telepon atau email. Tugas ini sangat melekat pada fungsi Teller dan Customer Service. Vinny, dkk (2015) dalam penelitiannya mengatakan Teller dan Customer Service merupakan frontliner di Bank Rakyat Indonesia Unit Karombasan yang berperan aktif untuk melayani nasabah dengan $3 \mathrm{~S}$, yaitu senyum, sapa, dan salam. Teller yang berperan untuk bertransaksi penyetoran dan penarikan uang tunai, melayani setoran BPJS, melayani pembayaran oriflamme, dan pembukaan overbooking nomor rekening nasabah yang terblokir, sedangan Customer Service berperan untuk melayani nasabah dalam pembukaan rekening pertama untuk melakukan penabungan di bank, melayani nasabah dengan ramah, senyum dan penuh kesabaran.

\section{Digitalisasi Perbankan}

Penelitian yang dilakukan oleh Kholis (2018) menunjukkan bahwa industri perbankan dalam memberikan layanan harus beradaptasi dengan perkembangan teknologi untuk memberikan kemudahan yang diinginkan oleh nasabah terhadap layanan perbankan. Perkembangan Financial Technology atau yang dikenal dengan istilah FinTech sejak tahun 2015 membuat perbankan harus aware dengan perkembangannya jika tidak ingin ditinggalkan nasabahnya yang dapat beralih ke lembaga keuangan lain.

Tidak hanya di Indonesia, digitalisasi perbankan merupakan sesuatu yang tidak terhindarkan lagi di berbagai belahan dunia. Anthony Rahul Golden S (2017) dalam tulisannya mengenai digitalisasi dalam sektor perbankan di India menyimpulkan "Due to the adoption of this digitalization, the banking 
sectors in India face some remarkable changes as well as hurdles. As we are in the digital era, it is not possible to avoid the growth and services or digital banking. Everyone uses the modern mobile device, called Smartphone, which is used to access the digital banking services to anyone at anywhere and at any time. Thus, digital banking is in the place of inevitable today". Jadi dapat disimpulkan bahwa digitalisasi perbankan saat ini bukan merupakan sebuah pilihan, melainkan telah menjadi suatu keharusan bila bank ingin terus bersaing memperebutkan pangsa pasar yang tersedia.

Digitalisasi perbankan tentunya berdampak positif bagi bank maupun nasabahnya. Transaksi yang tidak lagi dibatasi tempat dan waktu menjadi keuntungan yang signifikan bagi nasabah, sementara bagi perbankan kenaikan pendapatan yang berasal dari fee based income dan penurunan biaya tenaga kerja antara lain merupakan dampak positif yang dirasakan. Saviour dan Bornwell (2018) dalam rekomendasinya menuliskan "The banks make information on the benefits, costs, how the use etc available to the all customers and merchants. The use of e-banking has been found to be very beneficial to both the customer and the bank because the customer believes the service reduces transaction time; it is convenient and reduces the amount of cash to be carried in order to do a transaction which reduces the risk of losing cash. To the Bank, the use of e-banking has helped to reduce cost of handling the transactions including reduced cost of back room staff." Hal ini menekankan bahwa dampak e-banking terhadap tenaga kerja tidak bisa dihindari.

Mukhtar (2015) dalam penelitiannya mengenai persepsi nasabah di United Kingdom terhadap internet banking memberikan pertanyaan apakah responden menggunakan internet banking dan jawaban yang didapatkannya adalah bahwa "most of the participants (53\%) did not use internet banking. However, there were $47 \%$ participants who had experience of using internet banking services. Many earlier studies have revealed that internet banking is still not completely adopted by the customers. In fact, many earlier studies noted that users of the traditional banking system are more than internet banking users". Dalam penelitian lain di India, S.V. Mohana Sujana (2018) juga menyampaikan bahwa "Only 64\% of the population are aware of the digital banking services and make use of it". Jadi masih terdapat segmen nasabah yang tetap lebih menyukai dan merasa nyaman menggunakan layanan perbankan tradisional, terutama golongan nasabah yang berusia lebih tua. Oleh karena itu bank tetap memperhatikan keseimbangan layanan perbankan tradisionalnya mengingat potensi pasarnya yang masih cukup besar.

Digitalisasi perbankan juga memiliki beberapa tantangan dalam perkembangannya. S.V. Mohana Sujana (2018) menuliskan beberapa kekurangan dari digitalisasi perbankan yaitu Personal relationship between the bank officials and the customers has been minimized due to access from one place. As everything has been mobilised the security in protecting transaction has been reduced in such a case issues regarding transactions have been increased. There is an high risk in making transactions because identification of theft of encrypted software.

Tentunya hal-hal tersebut merupakan faktor-faktor yang harus diperhatikan dan menjadi bahan pertimbangan dunia perbankan dalam mengembangkan dan memodernisasi layanannya. Dalam penelitian di GCB Bank Ghana, Martin Otu Offei, dkk., (2016) menyampaikan bahwa tingginya biaya internet di Ghana menjadi salah satu hambatan bagi nasabah dalam menggunakan layanan internet banking. Hasil survey menyatakan "With regard to problems associated with internet banking, result indicate that the major challenge given by the respondents was that of high cost of internet service charges, representing $83 \%$. This was 
Salmah: Dampak Digitalisasi terhadap ...

followed by high cost of maintaining internet facility and high cost of getting reliable internet connectivity, representing $10 \%$ and $7 \%$ respectively".

\section{METODE PENELITIAN}

Penelitian ini menggunakan jenis penelitian deskriptif dengan metode deskriptif survey, karena penelitian ini meneliti fenomena yaitu tentang peran front office pada bisnis perbankan setelah adanya digitalisasi perbankan.

Populasi dalam penelitian ini adalah pimpinan cabang di Kota Bogor pada dua bank BUMN yang berjumlah 23 orang responden. Metode pengambilan sampel yang digunakan adalah metode sensus yaitu metode penarikan sampel di mana semua anggota populasi dijadikan sebagai sampel. Perwakilan populasi yang dijadikan sampel dalam penelitian ini adalah Pimpinan cabang Bank $A B C$ di Kota Bogor dan pimpinan cabang Bank XYZ di Kota Bogor.

Berdasarkan bentuknya, jenis data yang digunakan dalam penelitian ini adalah data kualitatif dan data kuantitatif. Data kualitatif merupakan data yang diperoleh melalui wawancara dengan pihak perbankan dan penyebaran kuesioner, sedangkan data kuantitatif yang digunakan merupakan data mengenai jumlah transaksi nasabah melalui teller dan customer service, jumlah transaksi nasabah yang menggunakan digital banking, dan lain-lain. Sedangkan berdasarkan sumbernya, data yang digunakan adalah data sekunder dan data primer. Data sekunder pada penelitian ini diperoleh secara manual dari Bank XYZ Cabang Kota Bogor dan Bank $A B C$ Cabang Kota Bogor, sedangkan data primer pada penelitian ini berasal dari responden yaitu para pimpinan cabang Bank XYZ di Kota Bogor dan Bank ABC di Kota Bogor.

Metode pengolahan data yang digunakan dalam penelitian ini adalah statistik deskriptif yakni statistik yang digunakan untuk menganalisis data dengan cara mendeskripsikan atau menggambarkan data yang telah terkumpul sebagaimana adanya tanpa bermaksud membuat kesimpulan yang berlaku umum atau generalisasi (Wahyudin, 2018). Data dari hasil kuesioner akan diolah dengan menggunakan SPSS versi 20.0. Setelah melakukan pengolahan hasil kuesioner, selanjutnya dilakukan analisis dengan menggunakan data yang diperoleh dari pihak Bank didukung dengan data hasil kuesioner yang telah diolah sehingga dapat diperoleh informasi yang lengkap dari sisi kualitatif dan kuantitatif sehingga diperoleh kesimpulan yang tepat.

\section{HASIL PENELITIAN DAN PEMBAHASAN}

\section{Analisa Data Kuantitatif}

Berdasarkan data yang diperoleh dari Bank ABC Cabang Kota Bogor dan Bank XYZ Cabang Kota Bogor, tren penggunaan transaksi digital banking pada kedua cabang bank tersebut melalui produk e-banking yaitu internet banking dan m-banking menunjukkan kenaikan seperti terlihat pada tabel 1 berikut :

Tabel 1. Jumlah Transaksi Nasabah Dengan M-Banking

\begin{tabular}{cccc}
\hline No. & Tahun & $\begin{array}{c}\text { Bank ABC Cabang } \\
\text { Kota Bogor }\end{array}$ & $\begin{array}{c}\text { Bank XYZ Cabang } \\
\text { Kota Bogor }\end{array}$ \\
\hline 1 & 2016 & 1.281 .350 & 1.917 .157 \\
\hline 2 & 2017 & 1.423 .722 & 2.617 .821 \\
\hline 3 & 2018 & 1.581 .913 & 3.337 .980 \\
\hline
\end{tabular}

Sumber: Bank ABC Cabang Kota Bogor dan Bank XYZ Cabang Kota Bogor, 2019

Data pada Tabel 1 di atas menunjukkan setiap tahunnya penggunaan smartphone untuk melakukan transaksi perbankan semakin meningkat melalui $\mathrm{m}$-banking baik pada Bank ABC Cabang Kota Bogor maupun pada Bank XYZ Cabang Kota Bogor. Selain produk m-banking, internet banking juga menjadi salah satu produk elektronik banking yang banyak diminati oleh nasabah karena dapat diakses dengan mudah melalui browser tanpa harus menggunakan aplikasi. Pada tabel 2 dibawah terlihat bahwa penggunaan internet banking untuk bertransaksi oleh 
nasabah pada Bank ABC Cabang Kota Bogor mengalami kenaikan dari tahun 2016 sampai tahun 2018 dengan persentase kenaikan per tahun mencapai $11 \%$. Namun, pada Bank XYZ Cabang Kota Bogor transaksi melalui internet banking justru mengalami penurunan dari tahun 2016 sampai tahun 2018, tetapi mengalami kenaikan yang cukup signifikan pada nasabah yang menggunakan m-banking. Hal ini menunjukkan preferensi nasabah Bank $\mathrm{XYZ}$ yang lebih menyukai m-banking dibandingkan internet banking karena Bank XYZ banyak mensasar nasabah dari kalangan wirausahawan muda.
Tabel 2. Jumlah Transaksi Nasabah Dengan Internet Banking

\begin{tabular}{cccc}
\hline No. Tahun & $\begin{array}{c}\text { Bank ABC } \\
\text { Cabang Kota } \\
\text { Bogor }\end{array}$ & $\begin{array}{c}\text { Bank XYZ } \\
\text { Cabang Kota } \\
\text { Bogor }\end{array}$ \\
\hline 1 & 2016 & 51.574 & 740.872 \\
\hline 2 & 2017 & 57.304 & 579.943 \\
\hline 3 & 2018 & 63.671 & 496.861 \\
\hline
\end{tabular}

Sumber: Bank ABC Cabang Kota Bogor dan Bank XYZ Cabang Kota Bogor, 2019

Selain kenaikan pada jumlah transaksi, penggunaan e-banking dengan produk m-banking dan internet banking dari sisi total transaksi juga mengalami kenaikan seperti terlihat pada tabel dibawah ini:

Tabel 3. Total Transaksi Nasabah Dengan M-Banking dan Internet Banking (Dalam Milyar)

\begin{tabular}{cccccc}
\hline \multirow{2}{*}{ No. } & Tahun & \multicolumn{2}{c}{ M-Banking } & \multicolumn{2}{c}{ Internet Banking } \\
\cline { 3 - 6 } & $\begin{array}{c}\text { Cabang Kota } \\
\text { Bogor }\end{array}$ & $\begin{array}{c}\text { Bank XYZ } \\
\text { Cabang } \\
\text { Kota Bogor }\end{array}$ & $\begin{array}{c}\text { Bank ABC } \\
\text { Cabang Kota } \\
\text { Bogor }\end{array}$ & $\begin{array}{c}\text { Bank XYZ Cabang } \\
\text { Kota Bogor }\end{array}$ \\
\hline 1 & 2016 & Rp1.400 & Rp2.556 & Rp29 & Rp1.169 \\
\hline 2 & 2017 & Rp1.556 & Rp3.589 & Rp32 & Rp1.118 \\
\hline 3 & 2018 & Rp1.729 & Rp5.255 & Rp36 & Rp1.054 \\
\hline
\end{tabular}

Sumber: Bank ABC Cabang Kota Bogor dan Bank XYZ Cabang Kota Bogor, 2019

Data transaksi e-banking pada Bank $A B C$ Cabang Kota Bogor dan Bank XYZ Cabang Kota Bogor pada tabel 3 di atas menunjukkan bahwa tipe nasabah sudah mulai beralih menggunakan produk dan fasilitas e-banking yang ditawarkan oleh bank. Dari kedua cabang bank terlihat bahwa produk $m$-banking lah yang saat ini banyak digunakan oleh nasabah pada kedua bank tersebut. Hal ini tidaklah aneh, melihat perkembangan teknologi pada smartphone dan murahnya biaya kuota internet membuat smartphone menjadi pusat segala aktivitas bagi manusia saat ini. Melalui gadget yang dimiliki, nasabah bisa melakukan transaksi keuangannya di manapun dan kapanpun.
Kenaikan transaksi pada produk $m$-banking ini, di mana nasabah dapat melakukan transfer, pembayaran tagihan, cek saldo, belanja, investasi,dll, membuat nasabah tidak lagi perlu datang ke kantor cabang untuk menemui teller atau customer service untuk membantu nasabah dalam melakukan transaksi. Fenomena kenaikan penggunaan transaksi digital pada Bank XYZ Cabang Kota Bogor ternyata memberikan pengaruh signifikan terhadap kunjungan nasabah ke teller, seperti terlihat pada tabel di bawah ini: 
Salmah: Dampak Digitalisasi terhadap ...

Tabel 4. Data Transaksi Nasabah melalui Teller Pada Bank XYZ Cabang Kota Bogor

\begin{tabular}{lccc}
\hline \multicolumn{1}{c}{ Nama Cabang } & 2016 & 2017 & 2018 \\
\hline $\begin{array}{l}\text { Bank XYZ Cabang } \\
\text { Juanda }\end{array}$ & 130.827 & 97.584 & 95.152 \\
\hline $\begin{array}{l}\text { Bank XYZ Cabang } \\
\text { K. Muslihat }\end{array}$ & 118.976 & 93.852 & 75.378 \\
\hline $\begin{array}{l}\text { Bank XYZ Cabang } \\
\text { Suryakencana }\end{array}$ & 41.498 & 34.553 & 33.257 \\
\hline $\begin{array}{l}\text { Bank XYZ Cabang } \\
\text { Wr. Jambu }\end{array}$ & 69.127 & 57.072 & 58.356 \\
\hline $\begin{array}{l}\text { Bank XYZ Cabang } \\
\text { Tajur }\end{array}$ & 61.503 & 52.919 & 51.723 \\
\hline $\begin{array}{l}\text { Bank XYZ Cabang } \\
\text { Pajajaran }\end{array}$ & 55.793 & 46.589 & 41.230 \\
\hline $\begin{array}{l}\text { Bank YZ Cabang } \\
\text { Pasar Anyar }\end{array}$ & 58.237 & 50.068 & 43.743 \\
\hline $\begin{array}{l}\text { Bank YZ Cabang } \\
\text { Ciluar }\end{array}$ & 54.071 & 47.225 & 46.583 \\
\hline $\begin{array}{l}\text { Bank XYZ Cabang } \\
\text { Sholeh Iskandar }\end{array}$ & 60.145 & 46.082 & 45.105 \\
\hline $\begin{array}{l}\text { Bank XYZ Cabang } \\
\text { Cibubur }\end{array}$ & 66.468 & 55.678 & 53.451 \\
\hline $\begin{array}{l}\text { Bank XYZ Cabang } \\
\text { Nirwana } \\
\text { Residence }\end{array}$ & 34.609 & 30.932 & 28.233 \\
\hline $\begin{array}{l}\text { Bank XYZ Cabang } \\
\text { Semplak }\end{array}$ & 15.858 & 17.945 & 24.344 \\
\hline \multicolumn{1}{|c}{ Total } & 767.112 & 630.499 & 596.555 \\
\hline \begin{tabular}{l} 
Sumber Bank XYZ Cabang Kota B090 \\
\hline
\end{tabular} & 2019 \\
\hline
\end{tabular}

Sumber: Bank XYZ Cabang Kota Bogor, 2019

Tabel 4. menunjukkan bahwa dari total 12 Cabang Bank XYZ yang berada di kota Bogor, terilihat pada 10 cabang kunjungan nasabah untuk melakukan transaksi melalui teller dari tahun ke tahun mengalami penurunan, hanya 1 cabang yang mengalami kenaikan per tahunnya yaitu cabang semplak.

Jika pada Bank XYZ Cabang Kota Bogor terjadi penurunan aktifitas transaksi nasabah melalui teller, hal ini tidak terlihat pada Bank $A B C$ Cabang Kota Bogor. Berdasarkan data yang diperoleh dari Bank $A B C$ Cabang Kota Bogor terlihat bahwa jumlah transaksi yang dilakukan oleh nasabah melalui teller dari tahun 2016 ke tahun 2018 mengalami kenaikan meski hanya mencapai $10 \%$. Kenaikan jumlah transaksi serta volume transaksi melalui m-banking pada Bank $A B C$ Kota Bogor tidak memberikan dampak yang signifikan kepada transaksi yang dilakukan nasabah melalui teller, begitu juga dengan jumlah nasabah yang mengunjungi customer service pada Bank ABC Cabang Kota Bogor terlihat dari tahun 2016 hingga 2018 tetap mengalami kenaikan seperti terlihat pada tabel berikut:

Tabel 5. Data Transaksi Nasabah melalui Teller dan Customer Service Pada Bank ABC Cabang Kota Bogor

\begin{tabular}{cccc}
\hline No & Tahun & $\begin{array}{c}\text { Jumlah } \\
\text { Transaksi Via } \\
\text { Teller }\end{array}$ & $\begin{array}{c}\text { Jumlah Transaksi } \\
\text { Via Customer } \\
\text { Service }\end{array}$ \\
\hline 1 & 2016 & 1.216 .800 & 296.400 \\
\hline 2 & 2017 & 1.318 .200 & 311.220 \\
\hline 3 & 2018 & 1.456 .000 & 405.600 \\
\hline Sumber: Bank ABC Cabang Kota Bogor, 2019 \\
\end{tabular}
customer service pada Bank ABC Cabang Kota Bogor yang tetap meningkat sejak tahun 2016 hingga 2018 berbanding terbalik dengan jumlah karyawan front office yang mana teller dan customer service termasuk didalamnya. Total dari 11 Cabang Bank $A B C$ yang ada di Kota Bogor, total jumlah karyawan front office pada Bank ABC Cabang Kota Bogor setiap tahun mengalami penurunan seperti terlihat pada tabel 6 berikut:

Tabel 6. Jumlah Karyawan Front Office Bank ABC Cabang Kota Bogor

\begin{tabular}{cccc}
\hline No. & Tahun & Jumlah Teller & $\begin{array}{c}\text { Jumlah } \\
\text { Customer } \\
\text { Service }\end{array}$ \\
\hline 1 & 2016 & 85 & 45 \\
\hline 2 & 2017 & 67 & 37 \\
\hline 3 & 2018 & 53 & 30 \\
\hline \multicolumn{4}{l}{ Sumber: Bank ABC Cabang Kota Bogor, 2019 }
\end{tabular}


Penurunan jumlah karyawan front office ini terjadi karena beberapa tugas dari teller dan customer service yang sudah dapat digantikan dengan teknologi melalui mesin dan aplikasi. Salah satunya adalah fungsi teller yang sekarang dapat dilakukan melalui Automatic Teller Machine (ATM), demikian halnya dengan fungsi customer service yang juga sudah mulai tergantikan beberapa perannya dengan mesin yang bernama CS Digital. Berdasarkan data sekunder yang diperoleh dari kedua bank terlihat bahwa digitalisasi yang saat ini diimplementasikan dalam setiap proses bisnis perbankan dan dalam pemberian layanan kepada nasabah secara langsung berdampak cukup signifikan terhadap fungsi pekerjaan front office yaitu teller dan customer service yang merupakan garda terdepan dari sistem layanan bank.

\section{Analisis Deskriptif}

Sumber data yang digunakan dalam penelitian ini adalah data sekunder dan data primer. Data primer diperoleh dari kuesioner yang diiisi oleh responden. Teknik yang digunakan dalam penarikan sampel menggunakan metode sensus yaitu metode penarikan sampel dimana semua anggota populasi dijadikan sebagai sampel. Jumlah responden dalam penelitian ini adalah sebanyak 23 orang, yang merupakan para Pimpinan Cabang Bank $A B C$ di Kota Bogor dan Pimpinan Cabang Bank XYZ di Kota Bogor. Berikut adalah kesimpulan dari hasil tanggapan responden:

Tabel 7. Hasil Tanggapan Responden

\begin{tabular}{|c|c|c|c|}
\hline No & Pernyataan & Tanggapan Responden & $\begin{array}{c}\text { Jumlah } \\
\text { Responden (\%) }\end{array}$ \\
\hline 1 & $\begin{array}{l}\text { Produk digital banking yang dimiliki pada } \\
\text { Cabang tempat Anda bekerja }\end{array}$ & $\begin{array}{l}\text { Internet Banking dan } \\
\text { M-Banking }\end{array}$ & $91 \%$ \\
\hline 2 & $\begin{array}{l}\text { Jumlah pengguna internet banking dan } \\
\text { m-banking pada tahun } 2019 \text { lebih tinggi } \\
\text { dibandingkan tahun } 2018\end{array}$ & lya & $100 \%$ \\
\hline 3 & $\begin{array}{l}\text { Transaksi yang sering digunakan nasabah } \\
\text { melalui internet banking dan m-banking }\end{array}$ & Pengiriman Uang & $70 \%$ \\
\hline 4 & $\begin{array}{l}\text { Jumlah nasabah yang mengunjungi teller } \\
\text { semakin berkurang pada tahun } 2019 \\
\text { dibanding tahun } 2018\end{array}$ & lya & $56 \%$ \\
\hline 5 & $\begin{array}{l}\text { Layanan yang digunakan nasabah melalui } \\
\text { teller }\end{array}$ & $\begin{array}{c}\text { Setoran dan Penarikan Uang } \\
\text { Tunai }\end{array}$ & $70 \%$ \\
\hline 6 & $\begin{array}{l}\text { Jumlah nasabah yang mengunjungi Customer } \\
\text { Service semakin berkurang pada tahun } 2019 \\
\text { dibanding tahun } 2018\end{array}$ & iya & $52 \%$ \\
\hline 7 & $\begin{array}{l}\text { Layanan yang sering digunakan nasabah } \\
\text { melalui Customer Service }\end{array}$ & $\begin{array}{l}\text { Pembukaan dan Penutupan } \\
\text { Rekening }\end{array}$ & $57 \%$ \\
\hline 8 & $\begin{array}{l}\text { Apakah internet banking dan mobile banking } \\
\text { dapat menggantikan peran frontliner }\end{array}$ & iya & $70 \%$ \\
\hline 9 & $\begin{array}{l}\text { Apakah jumlah teller akan berkurang dalam } 5 \\
\text { tahun ke depan }\end{array}$ & iya & $78 \%$ \\
\hline 10 & $\begin{array}{l}\text { Apakah jumlah customer service akan } \\
\text { berkurang dalam } 5 \text { tahun kedepan }\end{array}$ & iya & $61 \%$ \\
\hline
\end{tabular}

Sumber: Hasil olahan kuesioner, 2019 
Salmah: Dampak Digitalisasi terhadap ...

Berdasarkan hasil penyebaran kuesioner kepada para pimpinan cabang pada Bank $A B C$ Cabang Kota Bogor dan Bank XYZ Cabang Kota Bogor, terlihat bahwa terjadi penurunan jumlah nasabah yang mengunjungi Teller dan Customer Service tiap tahunnya pada kedua bank tersebut. Penurunan jumlah pengunjung ini diikuti dengan meningkatnya jumlah transaksi melalui e-banking, yaitu internet banking dan $m$-banking pada kedua bank seperti pada tabel berikut:

Tabel 8. Jumlah Transaksi Nasabah Dengan M-Banking

\begin{tabular}{cccc} 
No. & Tahun & Bank ABC & Bank XYZ \\
\hline 1 & 2016 & 1.281 .350 & 1.917 .157 \\
\hline 2 & 2017 & 1.423 .722 & 2.617 .821 \\
\hline 3 & 2018 & 1.581 .913 & 3.337 .980 \\
\hline
\end{tabular}

Sumber: Bank ABC Cabang Kota Bogor dan Bank XYZ Cabang Kota Bogor, 2019

Tabel 9. Jumlah Transaksi Nasabah Dengan Internet Banking

\begin{tabular}{cccc}
\hline No. & Tahun & Bank ABC & Bank XYZ \\
\hline 1 & 2016 & 51.574 & 740.872 \\
\hline 2 & 2017 & 57.304 & 579.943 \\
\hline 3 & 2018 & 63.671 & 496.861 \\
\hline
\end{tabular}

Sumber: Bank ABC Cabang Kota Bogor dan Bank XYZ Cabang Kota Bogor, 2019

Dilihat dari jenis transaksi yang sering dilakukan oleh nasabah melalui teller pada kedua bank, 70\% responden menyatakan bahwa transaksi setoran dan penarikan uang tunai merupakan transaksi yang paling sering dilakukan oleh nasabah. Hal ini dapat diartikan bahwa untuk transaksi seperti pengiriman uang/transfer antar bank, transfer ke bank lain, pembayaran tagihan, pengisian pulsa, dan lainnya dilakukan dengan menggunakan e-banking yaitu m-banking dan internet banking sesuai dengan jawaban responden yang menyatakan bahwa jumlah transaksi yang sering digunakan nasabah via m-banking dan internet banking pada kedua bank adalah
Pengiriman Uang (Pemindahbukuan/SKN/ RTGS/Valas). Sedangkan untuk setoran dan penarikan tunai saat ini sudah bisa dilakukan melalui mesin ATM. Nasabah yang datang mengunjungi teller untuk melakukan setoran dikarenakan jumlah setoran via mesin ATM yang terbatas jumlahnnya, begitu juga dengan penarikan uang tunai yang dilakukan melalui teller adalah penarikan di atas jumlah atau limit mesin ATM.

Transaksi yang sering dilakukan oleh nasabah melalui customer service pada kedua bank sebanyak $57 \%$ responden menyatakan bahwa pembukaan dan penutupan rekening adalah transaksi yang sering dilakukan nasabah melalui customer service, dan $43 \%$ responden menjawab lainnya yaitu seperti komplain nasabah tentang atm yang tidak bisa digunakan atau komplain tentang produk bank, penggantian kartu, penggantian pin, pembukaan blokir kartu atm, dan cetak buku tabungan. Saat ini untuk beberapa transaksi yang dilakukan melalui Customer service sudah mulai didukung oleh mesin yang bernama CS Digital. Namun, pada Cabang Bank $A B C$ dan $X Y Z$ di Kota Bogor belum ditemukan mesin ini, baru hanya terlihat satu bank swasta di Kota Bogor yang sudah mulai menggunakan mesin ini. Akan tetapi, saat ini pembukaan dan penutupan rekening tidak harus datang berkunjung ke kantor cabang, tapi bisa juga dilakukan melalui aplikasi yang dibuat oleh masing-masing bank yang dapat didownload melalui app store atau playstore.

Saat ini pada bisnis perbankan transaksi non-cash menjadi kebutuhan bagi nasabah bukan lagi sekedar produk pelengkap. Pengembangan fitur-fitur layanan dengan penggunaan teknologi untuk merespon kebutuhan nasabah terus dikembangkan, bahkan dalam hal layanan pembukaan rekening dapat dilakukan melalui aplikasi yang dapat didownload melalui HP Android melalui playstore. Bank $A B C$ dan Bank XYZ Cabang Kota Bogor juga telah mengkampanyekan untuk melakukan transaksi apapun melalui aplikasi online via android yang mereka 
kembangkan. Inilah yang menjadi kekhawatiran baru pada Sumber Daya Manusia di dunia perbankan, bahwa semakin hari teknologi akan semakin menggantikan pekerjaan-pekerjaan yang saat ini dilakukan oleh manusia. Dan saat ini sudah begitu terasa pada front office yaitu teller dan customer service. Hal ini dibenarkan oleh para pimpinan cabang Bank ABC dan Bank XYZ di Kota Bogor dimana sebesar $78 \%$ responden menyatakan bahwa dalam 5 tahun ke depan fungsi teller akan semakin berkurang, dan $61 \%$ menyatakan bahwa fungsi customer service dalam 5 tahun kedepan juga akan semakin berkurang. Para Pimpinan Cabang Bank ABC dan Bank XYZ di Kota Bogor yang merupakan responden dalam penelitian ini juga menyatakan bahwa e-banking akan menggantikan peran teller dan customer service dalam pemberian layanan kepada nasabah. Melalui beberapa analisa di atas maka dapat terlihat jelas bahwa peran teller dan customer service yang sering dikenal dengan istilah front office dalam bisnis perbankan mulai tergantikan dengan digitalisasi bisnis yang digunakan oleh perusahaan, dan dalam kurun waktu beberapa tahun ke depan bukan tidak mungkin peran front office akan hilang dan tergantikan.

Hasil penelitian ini sesuai dengan penelitian Wike dan Fika (2018) pada BTPN Syariah, yang mana penggunaan sistem digitalisasi pada proses operasionalnya memberi dampak negatif yaitu adanya pengurangan karyawan tetap dibagian operasional yang digantikan dengan karyawan outsourcing, pengurangan kantor cabang KFO yang tadinya terdapat 8 KFO di wilayah 3 Cirebon setelah digitalisasi menggunakan aplikasi m-prorspera Roll Out akan di-mapping menjadi 2 KFO yang akan beroperasi.

\section{PENUTUP}

Berdasarkan penelitian yang telah dilakukan, maka dapat diambil kesimpulan. Pertama, Seiring perkembangan teknologi dan munculnya generasi milenial, perbankan dihadapkan pada tantangan untuk menyederhanakan layanannya. Layanan perbankan yang diharapkan terutama dalam hal kemudahan, kecepatan dan yang paling penting adalah dapat dilakukan kapan saja dan di mana saja. Hal ini membuat perkembangan digitalisasi perbankan semakin meningkat. Kedua, perkembangan transaksi perbankan yang dilakukan melalui mobile banking dan internet banking membuat digitalisasi perbankan menjadi salah satu fokus utama perbankan dalam usaha mempertahankan persaingan yang semakin ketat dalam industri perbankan. Ketiga, dampak lain dari digitalisasi perbankan ini adalah semakin menurunnya kebutuhan perbankan akan fungsi front Office dalam hal ini Teller dan Customer Service. Hal ini karena semakin beragamnya cakupan transaksi yang dapat dilakukan secara online tanpa harus mengunjungi konter perbankan. Berdasarkan hasil analisis di atas serta keterbatasan dalam penelitian ini, maka dapat disarankan beberapa hal berikut. Pertama, penelitan selanjutnya disarankan untuk menambah variabel yang akan digunakan sebagai bahan dalam menganalisa dampak digitalisasi terhadap peran front office dan melakukan pengambilan data dari beberapa bank sehingga dapat dilakukan perbandingan. Kedua, penelitian selanjutnya disarankan untuk melihat dampak digitalisasi secara lebih luas tidak hanya pada peran front office namun juga dari sisi operasional perbankan sehingga diperoleh gambaran yang lebih akurat terhadap posisi banker pada industri perbankan. Ketiga, Perlu dilakukan penelitian lebih lanjut mengenai bidang-bidang kerja di perbankan, baik bidang kerja yang sudah ada maupun bidang kerja yang baru, yang dapat menjadi prioritas bagi fungsi Teller dan Customer Service untuk dipelajari. Bidang-bidang kerja tersebut diharapkan dapat menampung tenaga-tenaga Teller dan Customer Service yang semakin berkurang akibat dari dampak digitalisasi perbankan. 
Salmah: Dampak Digitalisasi terhadap ...

\section{REFERENSI}

Anthony, RGS. (2017). An Overview of Digitization in Indian Banking Sector. Indo-Iranian Journal of Scientific Research, 1(1), 209-212.

Aryani, W dan Aris, S. (2015). Perlindungan Hukum Pengguna Jasa Electronic Banking (E-Banking) di Tinjau dari Perspektif Hukum Pidana di Indonesia. Jurnal Pembaharuan Hukum, 11(1), 126-137.

Dewi, RI. (2016). Pengaruh E-Banking dan Kualitas Pelayanan Terhadap Loyalitas Nasabah Pada PT Bank BNI'46 Cabang Langsa. Jurnal Manajemen dan Keuangan, 5(2), 545-554.

Ikatan Bankir Indonesia. (2013). Memahami Bisnis Bank. Jakarta: PT Gramedia Pustaka Utama.

Irfan, W dan Salmah. (2018). Perancangan Teknologi Big Data Untuk Mendukung Digital Campaign Produk Perbankan (Studi Kasus Di PT Bank XYZ, Tbk). Laporan Akhir Hasil Penelitian Bersumber Dana Hibah Dikti. Universitas Pakuan.

Jacob, E dan Ratuate. (2018). Ancaman Revolusi Digital Bagi Pekerja Perbankan di Indonesia.https://www.kanigoro.com /artikel/ancaman-revolusi-digital-bagi-p ekerja-perbankan-di-indonesia/. [Diakses pada 25 Desember 2019].

Martin, OO dan Kwaku, NG. (2016). The Contribution Of Electronic Banking To Customer Satisfaction: A Case Of GCB
Bank Limited-Koforidua. International Journal of Managing Information Technology, 8(1), 1-11.

Mashood, M. (2015). Perceptions of UK Based Customers Toward Internet Banking In The United Kingdom. Journal Of Internet Banking and Commerce, 20(1), 1-38.

Kholis, N. (2018). Perbankan Dalam Era Baru Digital. Economicus, 9(1), 80-88.

Probank, November-Desember 2016 No 125 Tahun XXXIII, Hal 6-7.

Rinda, HK dan Elsy, R. (2017). Persepsi Nasabah Akan Layanan ATM dan E-Banking Dengan Metode TAM. Studia Informatika: Jurnal Sistem Informasi, 10(2), 89-102.

Saviour, L dan Bornwell, K. (2018). The Challenges of adopting The Use Of E-Banking to The Customers: The Case of Kasama District Banking Customers. Scholar Journal of Applied Sciences and Research, 1(2), 26-31.

S.V Mohana, S. (2018). Digitalization in Banking Sector. International Journal of Research and Analytical Reviews, 5(3), 333-337.

Vinny, RB, dkk. (2015). Peran Pelayanan Teller dan Customer Service Terhadap Kepuasan Pelanggan Pada Bank BRI Unit Karombasan Cabang Manado. Jurnal $E M B A, 3(3), 1126-1139$.

Wike, P dan Fika, N. (2018). Pengaruh Perubahan Sistem Digitalisasi Terhadap Kinerja Karyawan. Prosiding Seminar Nasional Multidisiplin, 1(1), 187-191. 